\title{
Do Seismic Signals Diverge at the Level of Cytotypes in Turkish Blind Mole Rats?
}

\author{
Faruk Çolak ${ }^{1}$ and Ferhat Matur ${ }^{2,3, *}$ \\ ${ }^{1}$ Department of Biology, Faculty of Arts and Science, Zonguldak Bülent Ecevit University, \\ Zonguldak, Turkey \\ ${ }^{2}$ Department of Biology, Faculty of Science, Dokuz Eylül University, Buca 35412, Izmir, \\ Turkey \\ ${ }^{3}$ Dokuz Eyül University, The Center for Faunistic and Floristic Research, Buca 35412, \\ Izmir, Turkey
}

\begin{abstract}
A B S T R A C T
Subterranean animals are limited in mobility and have reduced sensory ability due to living underground, and therefore are presented with a challenge to communicate. One solution is to use seismic signalling, by head drumming, to convey species-specific information. The lesser blind mole rats (Nannospalax sp.) are obligate subterranean rodents known for their remarkable chromosomal variation. In the present study, we investigated whether the structure of seismic signalling is different between the two species found in Turkey, Nannospalax leucodon and the N. xanthodon and whether it is associated with ecological, sex, temporal and chromosomal peculiarities. A cytotype of $N$. leucodon $(2 n=56)$ and three cytotypes of $N$. xanthodon, $(2 n=38,52$ and 60$)$ were used in the study. We observed no seismic signalling in $N$. leucodon. In $N$. xanthodon, the cytotype $2 n=60$ had faster rate of signalling in comparison to two other cytotypes $(2 n=38$ and $2 n=52)$, and the cytotypes also differed significantly in the structural components of their signals. There was no difference in signal pattern between different fundamental number variations within cytotypes. We observed temporal variation in seismic signals, but did not found any difference in signalling between the sexes, suggesting the signals are not used for mate recognition. In addition, the signalling structure was not associated with the climate and the soil types of the habitat of origin. We suggest that seismic communication by drumming may be used to recognize conspecifics within the same cytotype or species.
\end{abstract}

Article Information
Received 19 February 2019
Revised 12 May 2019
Accepted 27 August 2019
Available online 21 August 2020
Authors' Contribution
FÇ and FM collected samples together
in the field and designed the study. FC
made the behavioural experiments,
analysed the data and prepared draft.
FM edited the manuscript.
Key words
Head drumming, Vibrational
communication, Nannospalax
xanthodon, N. leucodon, Behavioural
isolation.

Revised 12 May 2019

Accepted 27 August 2019

FC and FM collected samples together

made the behavioural experiments,
analysed the data and prepared draft.

edited the manuscript.

Key words

communication, Nannospalax

xanthodon, N. leucodon, Behavioural

\section{INTRODUCTION}

$\mathrm{R}^{\mathrm{s}}$ eliable means of communication are essential between conspecifics or different taxonomic groups in practically all animals. Surface-dwelling species may communicate via a number of modes, including visual, audio and chemical; however, none of these are suitable for long-distance communication underground. Therefore, the means of communication in subterranean species is substantially adapted for living underground (Burda et al., 2007; Lange et al., 2007; Heth et al., 1985, 2002; Kimchi and Terkel, 2002; Heffner and Heffner, 1992, 1993). It is impressive that other sensory channels and organs can compensate for the lack of usual communication means (Nevo, 1990). Seismic signals, in particular, are produced in several ways in rodents: by the hind feet, as in Bathyergidae and Dipodidae (Mason and Narins, 2001), both the hind feet and incisors, as in Muridae (Giannoni et al., 1997; Bennett and Jarvis, 1988;

\footnotetext{
Corresponding author: ferhat.matur@gmail.com 0030-9923/2020/0006-2101 \$ 9.00/0

Copyright 2020 Zoological Society of Pakistan
}

Randall and Stevens, 1987; Ward and Randall; 1987, Dewsbury et al., 1978; Howe, 1978; Kenagy, 1973, 1976; Eisenberg, 1963), and by the head drumming, as in Spalacidae (Hrouzková et al., 2013; Li et al., 2001; Heth et al., 1987; Rado et al., 1987). We used the seismic signal term as the vibrations which animal produced it by hitting of a body parts to a substrate such as to the ground (Giannoni et al. 1997; Hrouzková et al., 2013; Rado et al., 1987; Randall, 199; Heth et al., 1987). Blind mole rats (Spalacidae) use seismic signalling to advertise their territory, as well as for orientation (Kimchi et al., 2005; Kimchi and Terkel, 2002, 2003; Heth et al., 1987, 1991), and possibly for species identification (Heth et al., 1987).

If seismic signalling is used for conspecific communication, it should differ between reproductively isolated species. While Dipodomys also produce speciesspecific drumming (Randall, 1997), head drumming signals were found to be specific to cytotypes in the Palestinian blind mole rat Nannospalax ehrenbergi in Israel (Heth et al., 1991; Nevo, 1985; Nevo et al., 1987; Rado et al., 1987).

Differences in communication signals among populations might depend on different ecological conditions (Seehausen et al., 1997; Marchetti, 1993), but 
can also serve as a mechanism of behavioural isolation (Boul et al., 2007; Seehausen et al., 1997). The differences in head drumming signalling were suggested to contribute to behavioural isolation and speciation among the different populations of the Palestinian BMR ( $N$. ehrenbergi) in Israel (Nevo et al., 1987).

In the Turkish fauna N. xanthodon is one of the three Nannospalax species, represented by more than 30 cytotypes. It is widely distributed in Turkey (Arslan et al., 2010, 2016; Arslan and Zima, 2014; Kankilic and Gürpınar, 2014; Matur et al., 2013; Hadid et al., 2012; Kandemir et al., 2012; Kryštufek et al., 2012; Kankılıç et al., 2010; Kryštufek and Vohrảlik 2009; Yiğit et al., 2006; Sözen et al., 2006; Matur and Sözen, 2005; Sözen, 2004). $N$. leucodon is also represented by multiple cytotypes, but only one $(2 n=56)$ is found in Turkey's Thrace (Sözen et al., 2006). Notably, the blind mole rats in Turkey occupy a wide range of habitats (e.g. different climate and soil types, Eken et al., 2005; Atalay, 2004).

Aside from a few reports on seismic signalling behaviour in N. ehrenbergi (Nevo et al., 1987; Rado et $a l .$, 1987), there has been no investigation on the other species of mole rats (Hrouzková et al., 2013; Li et al., 2001). We aimed to extend our knowledge on the head drumming signalling of two blind mole rats species found in Turkey ( $N$. leucodon and $N$. xanthodon) in respect to their chromosomal and ecological characteristics.

\section{MATERIALS AND METHODS}

\section{Sampling}

We examined 22 adult individuals of $N$. leucodon from 2 locations and 135 individuals of $N$. xanthodon from 10 locations in Turkey, characterized by different habitats. The individuals of of $N$. xanthodon belonged to three distinct cytotypes (Table I; Fig. 1). Karyotype of individual were determined by Matur et al. (2005) and (2013). In this study we collect identical coortdinates with those already published so we didn't repeat the karyotype.

\section{Housing}

Animals captured in the field were transferred individually to the laboratory in nest cages $(40 \times 25 \times 20$ $\mathrm{cm})$. A plastic tunnel protruded from one side of the cage to simulate a natural environment (underground tunnels) for the animals. Sawdust was added to the cages as burrowing material and bedding and the animals were fed carrots, lettuce, celery, apples, wheat, corn and cabbage ad libitum.

Table I.- Sampling localities of $N$. xanthodont $\left(1\right.$ to $10^{\text {th }}$ localites) and $N$. leucodon (11 and $12^{\text {th }}$ localities). Also the race name described by Arslan et al. (2016) were given in brackets under the locality names.

\begin{tabular}{|c|c|c|c|c|c|c|c|c|c|c|}
\hline \multirow[t]{2}{*}{$\begin{array}{l}\text { Locality } \\
\text { number }\end{array}$} & \multirow[t]{2}{*}{ Locality } & \multirow[t]{2}{*}{$2 n$} & \multirow[t]{2}{*}{$\mathbf{F N}$} & \multicolumn{2}{|c|}{$\mathbf{n}$} & \multicolumn{2}{|c|}{$\begin{array}{c}\text { No. of individuals } \\
\text { displaying seismic activity }\end{array}$} & \multirow[t]{2}{*}{$\begin{array}{c}\text { Climate } \\
\text { type* }\end{array}$} & \multirow[t]{2}{*}{$\begin{array}{l}\text { Soil } \\
\text { type }\end{array}$} & \multirow[t]{2}{*}{ Coordinates } \\
\hline & & & & $\mathbf{F}$ & $\mathbf{M}$ & Presence & Absence & & & \\
\hline 1 & Karacabey (turcicus) & 38 & 74 & 2 & 3 & - & 5 & S. humid & Clay & $40^{\circ} 14.844^{\prime} \mathrm{N} ; 28^{\circ} 15.212^{\prime} \mathrm{E}$ \\
\hline 2 & Bigadiç (turcicus) & & & 13 & 6 & 10 & 9 & S. arid & Clay & $39^{\circ} 22.203^{\prime} \mathrm{N} ; 27^{\circ} 59.543^{\prime} \mathrm{E}$ \\
\hline 3 & Çanakkale (turcicus) & & & 8 & 4 & 4 & 8 & S. arid & Clay & $40^{\circ} 10.349^{\prime} \mathrm{N} ; 26^{\circ} 29.054^{\prime} \mathrm{E}$ \\
\hline 4 & Yalova (abant) & $52^{\mathrm{a}}$ & 74 & 2 & 3 & 5 & 0 & Humid & Clay & $40^{\circ} 37.229^{\prime} \mathrm{N} ; 29^{\circ} 20.574^{\prime} \mathrm{E}$ \\
\hline 5 & Gerede (abant) & & 72 & 17 & 11 & 6 & 22 & S. humid & Clay & $40^{\circ} 47.631^{\prime} \mathrm{N} ; 32^{\circ} 9.387^{\prime} \mathrm{E}$ \\
\hline 6 & Korkuteli (vasvarii) & $60^{\mathrm{a}}$ & 74 & 4 & 2 & 5 & 1 & S. arid & Clay & $37^{\circ} 13.359^{\prime} \mathrm{N} ; 30^{\circ} 16.253^{\prime} \mathrm{E}$ \\
\hline 7 & Kapaklı (vasvarii) & & 78 & 13 & 14 & 15 & 12 & S. humid & Sand $^{d}$ & $40^{\circ} 50.033^{\prime} \mathrm{N} ; 32^{\circ} 26.724^{\prime} \mathrm{E}$ \\
\hline 8 & Oklubal (vasvarii) & & & 10 & 6 & 10 & 6 & S. arid & Clay $^{\mathrm{d}}$ & $39^{\circ} 48.951^{\prime} \mathrm{N} ; 30^{\circ} 14.108^{\prime} \mathrm{E}$ \\
\hline 9 & Gölbaşı (vasvarii) & & 80 & 4 & 5 & 6 & 3 & Arid $^{c}$ & Clay & $39^{\circ} 42.057^{\prime} \mathrm{N} ; 32^{\circ} 49.563^{\prime} \mathrm{E}$ \\
\hline 10 & Tavşanlı (vasvarii) & & & 4 & 5 & 9 & - & S. humid ${ }^{c}$ & Clay & $39^{\circ} 35.161^{\prime} \mathrm{N} ; 29^{\circ} 24.378^{\prime} \mathrm{E}$ \\
\hline Sub total & & & & 77 & 59 & 67 & 69 & & & \\
\hline 11 & Babaeski (leucodon) & 56 & 78 & 6 & 8 & - & 14 & S. humid & Clay & $41^{\circ} 29.212^{\prime} \mathrm{N} ; 26^{\circ} 57.585^{\prime} \mathrm{E}$ \\
\hline 12 & Lüleburgaz (leucodon) & & & 3 & 5 & - & 8 & S. humid & Clay & $41^{\circ} 21.356^{\prime} \mathrm{N} ; 27^{\circ} 33.278^{\prime} \mathrm{E}$ \\
\hline Sub total & & & & & 13 & & & & & \\
\hline Total & & & & 15 & 58 & & & & & \\
\hline
\end{tabular}

*S. Humid, semi-humid, ${ }^{a}$ Cytotypes where comparison has been made among the fundamental chromosomal arms (FN). ${ }^{b}$ Number of individual used for repeated measurements. 'Localities where comparison has been made among the climate types. ${ }^{\mathrm{d}}$ Localities where comparison has been made among the soil types. 


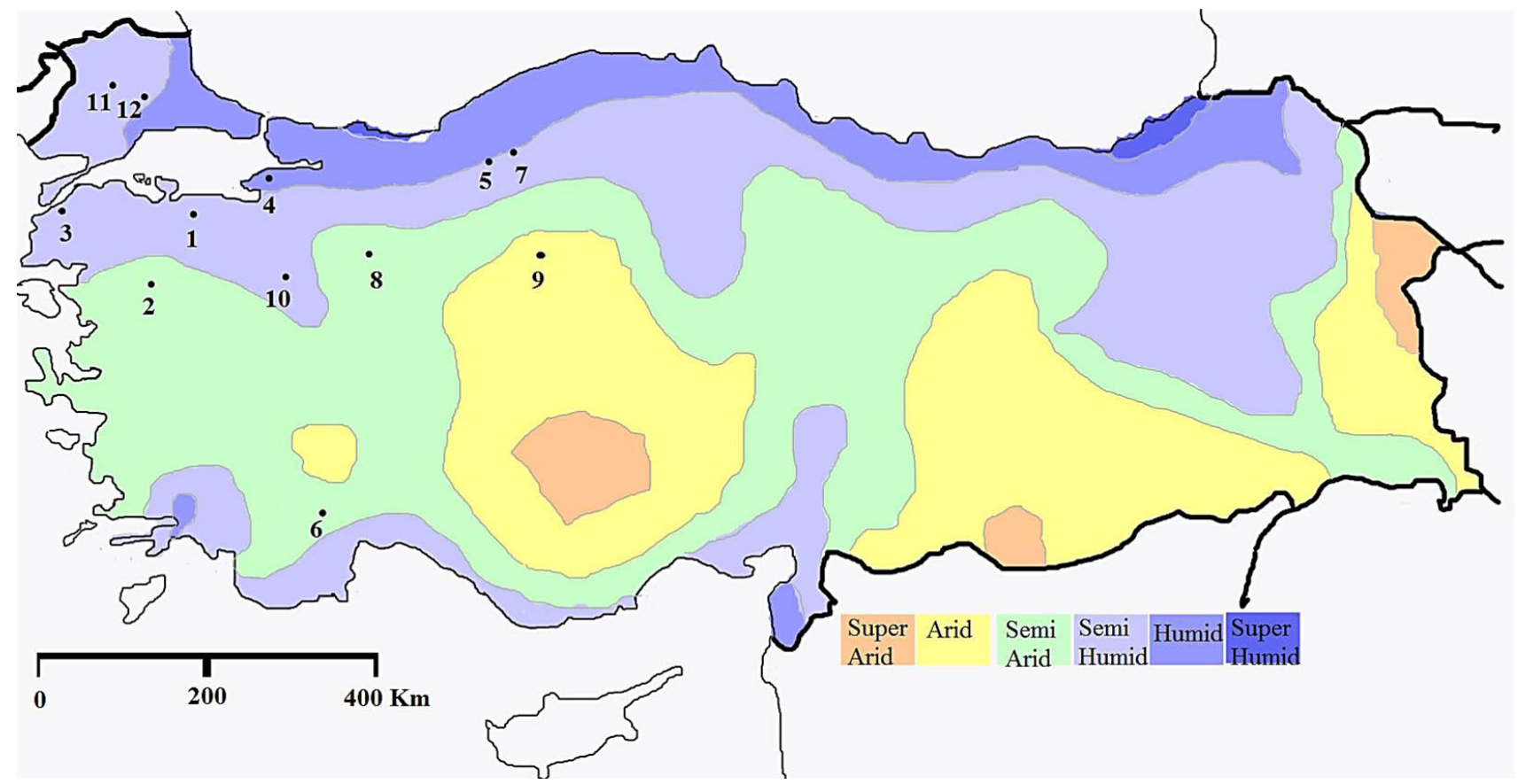

Fig. 1. Climate types of sampling localities of $N$. xanthodon and N. leucodon (Eken et al., 2005). The cytotype and locality information are given at Table I.

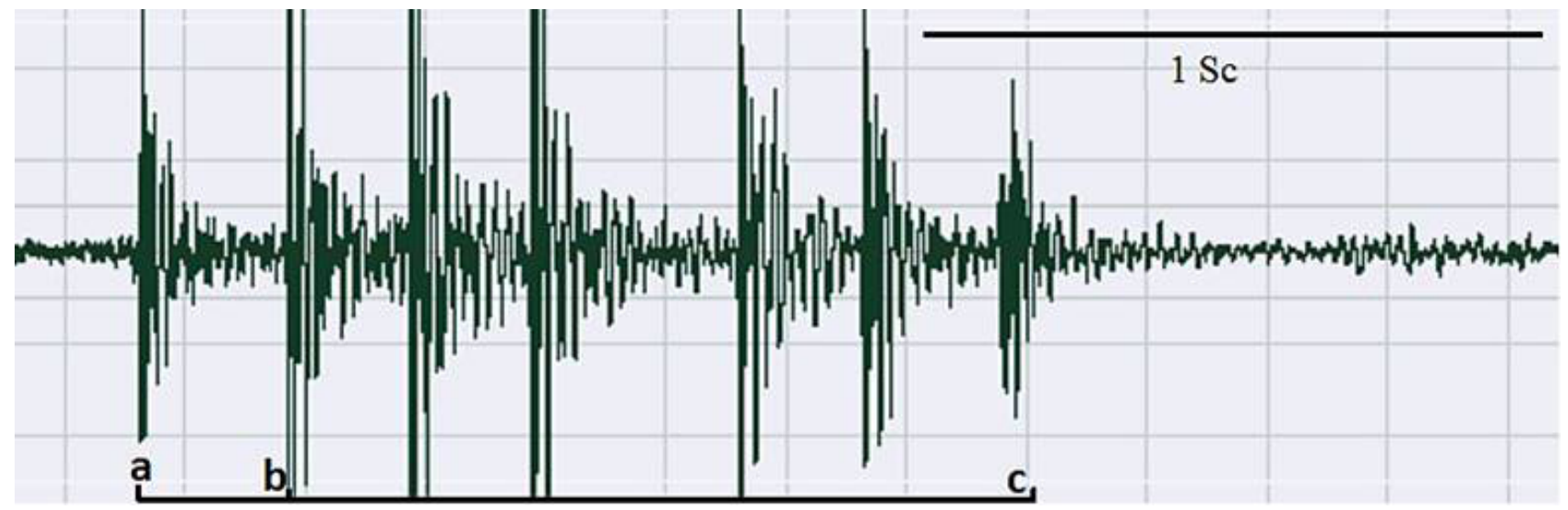

Fig. 2. Sonogram of a signal and parameters measured. PGS, pulse group size or width of a signal (elapsed time between the points of a-c; PG, pulse group in a burst, peak count between the points of a-c; and PU or signal speed, the one pulse or thump of animals in one burst, distance between two peaks, elapsed time between the points of $\mathrm{a}-\mathrm{b}$; Upper bar shows 1 sec (second).

\section{Procedure}

We performed all behavioural experiments in the laboratory, taking into account the previous findings by Rado et al. (1987), who showed that seismic signalling patterns in $N$. ehrenbergi did not differ between the field and the laboratory conditions. Animals were allowed a familiarization period of one week before the experiments began (Zuri and Terkel, 1996). As in kangaroo rats (Dipodomys), the drumming rates are expected to increase when animals are stressed (Randall and Matocq, 1997; Randall, 1991); therefore, we paid maximum attention to minimize the stress level. In earlier studies (Heth et al., 1987; Rado et al., 1987), the drumming behaviour was initiated by introducing two animals into the same tunnel, but other methods that avoid direct contact between animals are now preferred to avoid unnecessary injury. For that reason, we only allowed a single individual into the tunnel. The signals by each animal were recorded in its 
own environment and no other animal was used to prompt the drumming behaviour. A soft material made of sponge or Styrofoam was rubbed on the plastic tunnel to provoke drumming. This way, if the animal started drumming to mark its territory it did not have to defend itself against another animal. The signalling pattern was recorded by placing an audio recording device (SONY IC Recorder ICD-PX330 with integrated microphone) against the sidewall of the plastic tunnel. The recording was repeated two or three times per week and the entire experiment was completed within two months (15 repetitions). At the end of the experiment, the animals were euthanized (Leary et $a l .$, 2013), as it was not possible to return them back to their natural environment. Subsequently, we calculated the signal parameters with an audio analysis program Adobe Audition 3.0 (Riley, 2008) as described by Hrouzková et al. (2013), Rado et al. (1987), Randall (1997) and Heth et al. (1987). The calculated parameters from a signal set were as follows: PGS, pulse group size or width of a signal (elapsed time between the points of a-c; Fig. 2); PG, pulse group in a burst (peak count between the points of a-c; Fig. 2); and PU or signal speed, the one pulse or thump of animals in one burst, distance between two peaks (elapsed time between the points of $a-b$; Fig. 2). The signal or burst refers to the elapsed time between the points of $\mathrm{a}-\mathrm{c}$ and consists of the time between starting and ending points of the drumming of the blind mole rats as shown on Figure 2.

\section{Statistical analysis}

We first tested whether the differences in seismic signalling among individuals were not random by using the signals recorded during different sessions on different days. First, we applied ANOVA (SPSS 13) with repeated measurements for each animal for the PU parameter and a non-parametric Friedman test for the PGS and PG parameters (SPSS 13). Second, we tested if signal components varied by sex by using the t-test on the data for three different variables (PU, PGS, and PG). To test whether ecological characteristics have any effect on the seismic signal patterns, we performed the same testing within cytotypes. To test a single ecological variable per each step, we pooled together individuals with identical FN values from different localities. We used a total of 27 individuals from Kapakl $(2 n=60, \mathrm{FN}=78$, sandy soil type, locality no $=7$ in Fig. 1), and 16 animals from Oklubal $(2 n=60, \mathrm{FN}=78$, clayish soil type, locality no $=8$ on Fig. 1; Table I). We tested for the effects of climate by using a total of 9 individual from Gölbaşı $(2 n=60, \mathrm{FN}=80$, arid climate, locality no $=9$ in Fig. 1), and 9 individuals from Tavşanlı $(2 n=60, \mathrm{FN}=80$, semi-arid climate, locality no $=10$ on Fig. 1). Finally, we analyzed the variation in seismic signalling among all FN types within two cytotypes $(2 n=52$ : $\mathrm{FN}=72,74$ by the t-test and $2 n=60$ : $\mathrm{FN}=74,78,80$ by ANOVA) and among all cytotypes of $N$. xanthodon $(2 n=38,52$ and 60$)$ by ANOVA. The PCA was performed in $\mathrm{R}$ statistical software, using all three variables, to see whether the clustering pattern in individual data corresponded to cytotypes or to FN types in twodimensional space (Kassambara, 2016; Kassambara and Mundt, 2016; R Development Core Team, 2016).

The animals were treated in accordance with the guidelines of the Bülent Ecevit University Animal Experiments Local Ethic Committee; approval reference number 2012-03-25/01.

Table II.- Cytotypes comparison (ANOVA shows the results of three characters among cytotype characters. f: F value).

\begin{tabular}{lccccc}
\hline Variable & 2n & n & Mean & Test value & p-value \\
\hline PU & 38 & 10 & 0.115 & $103.499^{\mathrm{f}}$ & $0.000^{*}$ \\
& 52 & 11 & 0.117 & & \\
& 60 & 45 & 0.768 & & \\
PG & 38 & 10 & 4.642 & $41.205^{\mathrm{f}}$ & $0.000^{*}$ \\
& 52 & 11 & 8.085 & & \\
& 60 & 45 & 4.714 & & \\
PGS & 38 & 10 & 0.471 & $93.681^{\mathrm{f}}$ & $0.000^{*}$ \\
& 52 & 11 & 0.832 & & \\
& 60 & 45 & 0.293 & & \\
\hline
\end{tabular}

\section{RESULTS}

We did not observe any drumming behaviour in $N$. leucodon $(\mathrm{n}=22)$. In contrast, some individuals of $N$. xanthodon in each sampled locality displayed drumming behaviour (Table I). The numbers of individuals in Table I which displayed the drumming behaviour were 14, 11 and 45 for the cytotypes $2 n=38,52$ and 60 , respectively.

The ANOVA test among the three cytotypes showed significant differences in all variables $(p=0.000)$. When we performed a post-hoc test, the cytotype $2 n=60$ was statistically different from other cytotypes in terms of PU (signal velocity), with faster signal. While the PGS variable was different among all three cytotypes, the PG variable was the same for the $2 n=38$ and 60 ; but different for the $2 n=52$ cytotype (Table II). According to the PCA results the individuals with identical diploid numbers were grouped closely with each other in a two-dimensional space (Fig. 3). Comparisons of FN variations of the cytotypes $2 n=52(\mathrm{FN}=72$ and 74$)$ and $60(\mathrm{FN}=74,78$ and 80 ) did not show significant differences within $2 n=52$ and $2 n=60$ (Table III). 


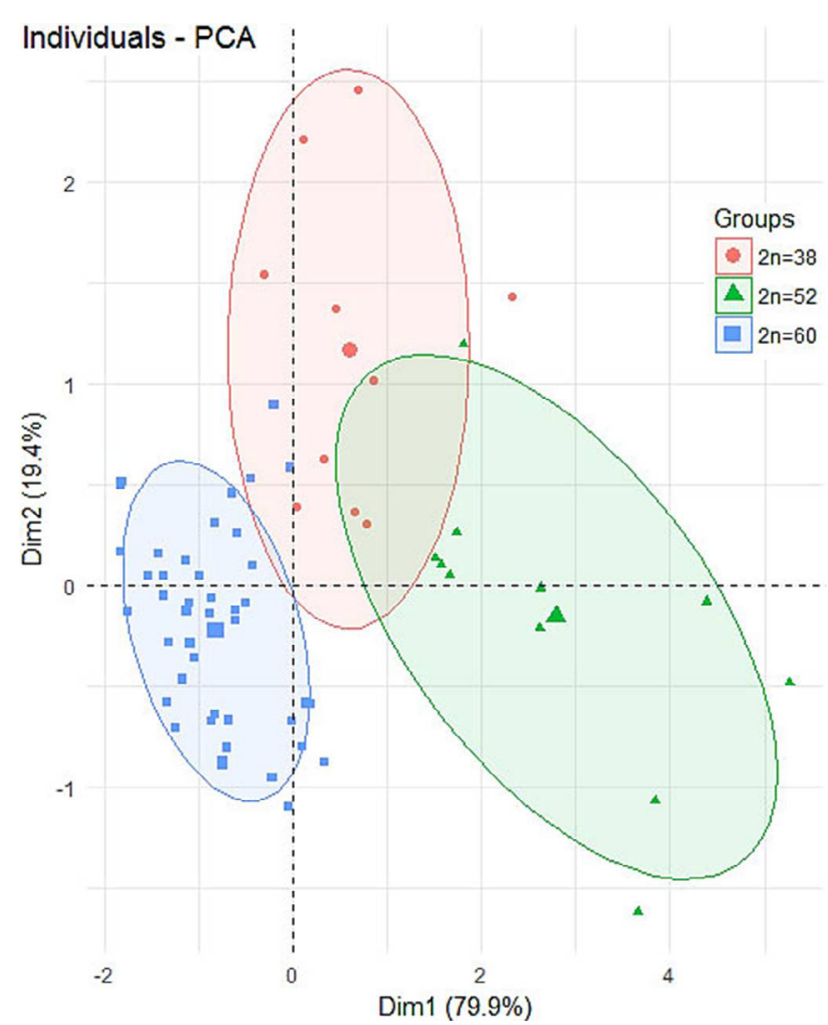

Fig. 3. Representation of individuals on a two-dimensional plane after PCA.

Table III.- FN comparison (ANOVA shows the results of three characters among $\mathrm{FN}$ variations. Comparisons in $2 n=52$ was calculated by t-test, but $F$ statistic was used for comparisons of three NF variation in $2 n=60$. $t$ : t value, f: $F$ value).

\begin{tabular}{lcccccc}
\hline Variable & 2n & FN & n & Mean & Test value & p-value \\
\hline PU & 60 & 74 & 5 & 0.758 & $0.201^{\mathrm{f}}$ & 0.819 \\
& & 78 & 20 & 0.766 & & \\
& & 80 & 15 & 0.783 & & \\
& 52 & 72 & 6 & 0.1121 & $-1.729^{\mathrm{t}}$ & 0.146 \\
& & 74 & 5 & 0.1234 & & \\
PG & 60 & 74 & 5 & 4.242 & $2.012^{\mathrm{f}}$ & 0.148 \\
& & 78 & 20 & 5.064 & & \\
& & 80 & 15 & 4.632 & & \\
& 52 & 72 & 6 & 8.333 & $0.496^{\mathrm{t}}$ & 0.626 \\
& & 74 & 5 & 7.787 & & \\
PGS & 60 & 74 & 5 & 0.245 & $2.042^{\mathrm{f}}$ & 0.144 \\
& & 78 & 20 & 0.318 & & \\
& & 80 & 15 & 0.299 & & \\
& 52 & 72 & 6 & 0.805 & $-0.392^{\mathrm{t}}$ & 0.710 \\
& & 74 & 5 & 0.865 & & \\
\hline
\end{tabular}

Among all three cytotypes, 13 out of the total of 60 individuals displaying drumming behaviours were evaluated for temporal variation. A total of 13 individuals (one with $2 n=38 / \mathrm{NF}=74$ and twelve with $2 n=60 / \mathrm{FN}=78$ were used for multiple measurements $(>0.05)$. Using repeated measurements tests for the same individuals, we found the difference in the peak number (PG) in only two individuals and no difference in the signal length (PGS). There was significant variation in the signal speed (PU) in all but two individuals.

We found no statistically significant difference in seismic signalling between sexes in all three variables (t-test, Table IV). For the ecological comparisons, t-test results showed no significant difference between the seismic signal patterns in the individuals from different soil and climate types (t-test, Table V).

Table IV.- Sex comparison (t-test comparisons of sexes. t: t value).

\begin{tabular}{lcccccc}
\hline Variable & 2n & F & M & $\begin{array}{c}\text { Mean } \\
\text { (female/male) }\end{array}$ & $\begin{array}{c}\text { Test } \\
\text { value }\end{array}$ & $\begin{array}{c}\text { p- } \\
\text { value }\end{array}$ \\
\hline PU & 38 & 6 & 4 & $0.98 / 0.119$ & $-3.70^{\mathrm{t}}$ & 0.13 \\
& 52 & 6 & 5 & $0.111 / 0.119$ & $-1.105^{\mathrm{t}}$ & 0.298 \\
& 60 & 25 & 20 & $0.79 / 0.77$ & $0.645^{\mathrm{t}}$ & 0.523 \\
PG & 38 & 6 & 4 & $0.510 / 0.420$ & $1.254^{\mathrm{t}}$ & 0.245 \\
& 52 & 6 & 5 & $0.792 / 0.739$ & $0.546^{\mathrm{t}}$ & 0.598 \\
& 60 & 25 & 20 & $0.294 / 0.284$ & $0.423^{\mathrm{t}}$ & 0.675 \\
PGS & 38 & 6 & 4 & $5.013 / 4.112$ & $1.49^{\mathrm{t}}$ & 0.196 \\
& 52 & 6 & 5 & $8.113 / 7.672$ & $0.568^{\mathrm{t}}$ & 0.584 \\
& 60 & 25 & 20 & $4.745 / 4.639$ & $0.324^{\mathrm{t}}$ & 0.748 \\
\hline
\end{tabular}

\section{DISCUSSION}

Social communication has a vital role mediating behaviour such as mate choice, territoriality, and kin selection. Because mating between individuals of different species can have negative fitness consequences, animals are expected to be under strong selection to produce and recognize species-specific mating signals (Ryan and Rand, 1993). Thus, the signals used for species recognition should show less variation across environmental and season factors. This should be especially true for blind mole rats (Nannospalax sp.), which live underground with no visual sensory ability and limited opportunity for dispersal. Indeed, our results show that $N$. xanthodon differ significantly in drumming components by cytotype and lend support to previous studies that show individuals can recognize species through seismic signals. 
Table V.- Ecological comparisons (t-test between ecological groups. $t$ : $t$ value).

\begin{tabular}{|c|c|c|c|c|c|c|c|c|}
\hline Variable & $2 n$ & FN & Locality & $\mathrm{n}$ & Mean & Soil/Climate & Test value & Sig \\
\hline \multirow[t]{4}{*}{ PU } & 60 & 78 & Kapaklı & 15 & 0.770 & Sandy soil & $-0.740^{t}$ & 0.467 \\
\hline & & 78 & Oklubal & 10 & 0.80 & Clay soil & & \\
\hline & & 80 & Gölbaşı & 6 & 0.740 & Arid & $-0.943^{t}$ & 0.366 \\
\hline & & 80 & Tavşanlı & 9 & 0.860 & Semi humid & & \\
\hline \multirow[t]{4}{*}{ PG } & 60 & 78 & Kapaklı & 15 & 4.715 & Sandy soil & $-0.780^{\mathrm{t}}$ & 0.444 \\
\hline & & 78 & Oklubal & 10 & 5.104 & Clay soil & & \\
\hline & & 80 & Gölbaşı & 6 & 4.517 & Arid & $0.41^{\mathrm{t}}$ & 0.968 \\
\hline & & 80 & Tavşanlı & 9 & 4.732 & Semi humid & & \\
\hline \multirow[t]{4}{*}{ PGS } & 60 & 78 & Kapaklı & 15 & 0.285 & Sandy soil & $-1.026^{\mathrm{t}}$ & 0.316 \\
\hline & & 78 & Oklubal & 10 & 0.324 & Clay soil & & \\
\hline & & 80 & Gölbaşı & 6 & 0.263 & Arid & $-0.492^{\mathrm{t}}$ & 0.652 \\
\hline & & 80 & Tavşanlı & 9 & 0.319 & Semi humid & & \\
\hline
\end{tabular}

The lack of drumming behaviour in samples of $N$. leucodon appears to be quite interesting since the seismic signalling is reported for many member of family Spalacidae, in particular for communication purposes (Hrouzková et al., 2013; Li et al., 2001; Nevo et al., 1987; Rado et al., 1987). Our total sample size for the $N$. leucodon was 20 individuals and this number is higher compared to many other locations of $N$. xanthodon distributed throughout the Asian part of Turkey. At the same time, drumming behaviour was not observed in only one locality of the cytotype $2 n=38$. It could be that the reason for the absence of drumming behaviour in $N$. leucodon and $2 n=38$ cytotype of $N$. xanthodon is similar. We suggest that a new independent experiment might be needed to get precise information on the drumming behaviour in N. leucodon, perhaps using large samples from different locations.

The comparison between cytotypes and FN may provide evolutionary insights. Seismic signals could be useful in kinship recognition. The different seismic signalling patterns per each cytotype implied that individuals may use seismic signalling to recognize conspecifics. The behaviours of individuals towards each other may be related to their genetic relatedness both within and between populations. Since the seismic signalling variations among different cytotypes of Palestinian blind mole rats were shown to be used for recognition of conspecifics, it was interpreted as a contribution to reproductive isolation between the cytotypes (Heth et al., 1987; Rado et al., 1987). Our results show that each cytotype of $N$. xanthodon showed as a clear cluster on the individual principle components plot (Fig. 3). Almost $80 \%$ of the variation could be explained by the differences between $2 n=60$ and the other two cytotypes. Similar to $N$. ehrenbergi, the seismic signal patterns in $N$. xanthodon varied by diploid chromosome numbers and may represent the means of species-specific communication.
Interestingly, the first PC axis revealed closer relationship between the cytotypes $2 n=38$ and $2 n=52$, and a slightly tighter clustering of individuals with cytotype $2 n=60$ (Fig. 1). This corresponds to a recent finding by Matur et al. (2019), who showed that $2 n=52$ and $2 n=38$ belong to the same Western Anatolian phylogentic clade, different from the Central Anatolian clade that contains $2 n=60$.

In the present study, we tested whether there is a difference in drumming patterns among individuals with different numbers of chromosome arms $(\mathrm{FN})$ within the same cytotypes $2 n=52(\mathrm{FN}=72$ and 74$)$ and $60(\mathrm{FN}=74,78$ and 80). Difference in FN variants may theoretically serve as a reproductive barrier between populations or mark population divergence. However, we found no statistically significant difference. This means that similar drumming signals are used by all individuals that belong to the same cytotypes and such similar signalling may prevent behavioural isolation among $\mathrm{FN}$ variants.

We found significant unexplained differences among the repeated measurements in the signal speed (PU) in most individuals. This result could not be caused by seasonal variation, since all recordings per each individual were performed within a short period of two months. Variation in diet regime is also an unlikely cause since all animals were given the same food at libitum. It is interesting that some animals did not display temporal variation. We conclude that this finding needs further investigation. Other variables (PG and PGS, with minor exceptions) remained constant for the same individuals over the entire experiment. We suggest that the drumming signalling patterns may be used as an additional taxonomic character to differentiate between cytotypes. However, other factors may affect the signalling pattern. For example, the footdrumming signals made by the kangaroo rats are affected by their social environment, and the variation is higher in juveniles than in adults (Randall and Matocq, 1997; 
Randall, 1991, 1995). We could not determine the age of individuals, as methods for reliable age verification in BMRs are non-existent or poorly developed (Puzachenko, 1996). Therefore we cannot exclude the possibility that some portion of variation between cytotypes in our study was linked to age. However, age alone cannot account for the strong differences in signalling pattern between the cytotypes.

Although mate choice has been proposed as one explanation for species-specific communication, we found that seismic signal structures were similar for both sexes (Table IV). It appears that there is no sexual dimorphism in $N$. xanthodon in terms of seismic signal structures (Table IV) and thus it is unlikely that this communication is under sexual selection. Blind mole rats are known to be solitary animals, and only one individual occupies a single nest, except during mating season or maternal care (Nevo, 1961). They defend their territories against intruders and they use seismic signals to define the borders of their territories (Zuri and Terkel, 1996). Heth et al. (1987) reported that the Palestinian blind mole rat $N$. ehrenbergii use seismic signals for territorial purposes. Our results suggest that seismic signals may also be used for territorial purposes by the Anatolian blind mole rat $N$. xanthodon.

The drumming signals of animals originated from different soil and climate types did not show any difference (Table V). We conclude that ecological factors play little or no role in shaping the seismic signalling of $N$. xanthodon

\section{CONCLUSION}

The seismic signalling structure of two mole rats species of Nannospalax in Turkey evaluated in the manuscript. The $N$. leucodon has not drumming behaviour based on our samplings and needs elaborately study across it distribution range in Turkey. Although the cytotypes of $N$. xanthodon in Turkey have ecological, sex and chromosomal variations (like FN), they have unique seismic signalling structure. We gave a description of some races of seismic signalling patterns of mole rats in Turkey first time and it must be study detailed in future in all Nannospalax cytotypes.

\section{ACKNOWLEDGEMENT}

This project has been supported by Bülent Ecevit University BAP 2012-10-06-01. We would like to thank Murat Sevindik, Sercan Irmak, Ortaç Çetintaş, Muhsin Çoğal and Tuğçe Ceylan for their help with collecting samples. Jamie Winternitz and Alexey Yanchukov helped with editing the first manuscript draft. This study is a part of the PhD thesis of Faruk Çolak (2015).
Statement of conflict of interest

The authors declare that there is no conflict of interests regarding the publication of this article.

\section{REFERENCES}

Arslan, A. and Zima, J., 2014. Karyotypes of the mammals of Turkey and neighbouring regions: A review. Folia Zool., 63: 1-62. https://doi. org/10.25225/fozo.v63.i1.a1.2014

Arslan, A., Kryštufek, B., Matur, F. and Zima J., 2016. Review of chromosome races in blind mole rats (Spalax and Nannospalax). Folia Zool., 65: 249301. https://doi.org/10.25225/fozo.v65.i4.a1.2016

Arslan, E., Gülbahçe, E., Arıkoğlu, H., Arslan, A., Bužan, E.V. and Kryštufek, B., 2010. Mitochondrial divergence between three cytotypes of the Anatolian Mole Rat, Nannospalax xanthodon (Nordmann, 1840) (Mammalia: Rodentia). Zool. Middle East, 50: 27-34. https://doi.org/10.1080/09397140.2010. 10638408

Atalay, A., 2004. Toprak tipleri ve Türkiye'nin genel toprak profilleri. Meteksan, Ankara.

Bennett, N.C. and Jarvis, J.U.M., 1988. The reproductive biology of the Cape mole-rat, Georychus capensis (Rodentia, Bathyergidae). J. Zool., 214: 95106. https://doi.org/10.1111/j.1469-7998.1988. tb04989.x

Boul, K.E., Funk, W.C., Darst, C.R., Cannatella, D.C. and Ryan, M.J., 2007. Sexual selection drives speciation in an Amazonian frog. Proc. R. Soc. Lond. B: Biol. Sci., 274: 399-406. https://doi. org/10.1098/rspb.2006.3736

Burda, H., Bruns, V. and Müller, M., 2007. Sensory adaptations in subterranean mammals. In: Evolution of subterranean mammals at the organismal and molecular levels (eds. E. Nevo and O.A. Reig). Alan R. Liss, Inc., New York, pp. 269-293.

Dewsbury, D.A., Estep, D.Q. and Oglesby, J.M., 1978. Copulatory behaviour and the initiation of pregnancy in Israeli gerbils (Meriones tristrami). Biol. Behav., 3: 243-257.

Eisenberg,J.F., 1963.Acomparative study of sand bathing behavior in heteromyid rodents. Behaviour, 22: 1623. https://doi.org/10.1163/156853963X00284

Eken, M., Ceylan A., Taştekin, A.T., Şahin, H. and Şensoy, S., 2005. Klimatoloji II. Ankara: Çevre ve Orman Bakanlığ Devlet Meteroloji İşleri Genel Müdürlügü. DMİ Yayınları, pp. 130 (In Turkish).

Giannoni, S., Marquez, R. and Borghi, C.E., 1997. Airbone and substrate-borne comunications of Microtus (Terricola) gerbei and M. (T.) 
duodecimcostatus. Theriologica, 42: 123-141. https://doi.org/10.4098/AT.arch.97-16

Hadid, Y., Németh, A., Snir, S., Pavlíček, T., Csorba, G., Kázmér, M., Major, Á., Mezhzherin, S., Rusin, M. and Coşkun, Y., 2012. Is evolution of blind mole rats determined by climate oscillations? PLoS One, 7: e30043. https://doi.org/10.1371/journal. pone. 0030043

Heffner, R.S. and Heffner, H.E., 1992. Hearing and sound localization in blind mole rats Spalax ehrenbergi. Hearing Res., 62: 206-216. https://doi. org/10.1016/0378-5955(92)90188-S

Heffner, R.S. and Heffner, H.E., 1993. Degenerate hearing and sound localization in naked mole rats (Heterocephalus glaber), with an overview of central auditory structures. J. comp. Neurol., 331: 418-433. https://doi.org/10.1002/cne.903310311

Heth, G., Frankenberg, E. and Nevo, E., 1986. Adaptive optimal sound for vocal communication in tunnels of a subterranean mammal (Spalax ehrenbergi). Experientia, 42: 1287-1289. https:// doi.org/10.1007/BF01946426

Heth, G., Frankenberg, E., Raz A. and Nevo, E., 1987. Vibrational communication in subterranean mole rats (Spalax ehrenbergi). Behav. Ecol. Sociobiol., 21: 31-33. https://doi.org/10.1007/BF00324432

Heth, G., Frankenberg, E., Pratt, H. and Nevo, E., 1991. Seismic communication in the blind subterranean mole-rat-patterns of head thumping and of their detection in the Spalax ehrenbergi super-species in Israel. J. Zool., 224: 633-638. https://doi. org/10.1111/j.1469-7998.1991.tb03791.x

Heth, G., Todrank J., Begall, S., Koch, R., Zilbiger, Y., Nevo, E., Braude, S.H. and Burda, H., 2002. Odours underground: Subterranean rodents may not forage" Blindly". Behav. Ecol. Sociobiol., 52: 53-58. https://doi.org/10.1007/s00265-002-0476-0

Hill, P.M., 2009. How do animals use substrateborne vibrations as an information source? Naturwissenschaften, 96: 1355-1371. https://doi. org/10.1007/s00114-009-0588-8

Howe, R.J., 1978. Agonistic behavior of three sympatric species of woodrats (Neotoma mexicana, $N$. albigula and N. stephensi. J. Mammal., 59: 780786. https://doi.org/10.2307/1380142

Hrouzková, E., Dvořáková, V., Jedlička, P. and Šumbera, R., 2013. Seismic communication in demon African mole rat Tachyoryctes daemon from Tanzania. J. Ethol., 31: 255-259. https://doi. org/10.1007/s10164-013-0374-0

Kandemir, I., Sözen, M., Matur, F., Kankılıç, T., Çolak, F., Özkurt, S. and Çolak, E., 2012. Phylogeny of species and cytotypes of mole rats (Spalacidae) in Turkey inferred from mitochondrial cytochrome $\mathrm{b}$ gene sequences. Folia Zool., 61: 25-33. https://doi. org/10.25225/fozo.v61.i1.a5.2012

Kankılıç, T. and Gürpınar, C., 2014. Revised classification design of the Anatolian species of Nannospalax (Rodentia: Spalacidae) using RFLP analysis. Turk. J. Zool., 38: 67-78. https://doi. org/10.3906/zoo-1301-38

Kankılıç, T., Kankılıç, T., Şeker, P.S., Çolak, R., Selvi E. and Çolak, E., 2010. Contributions to the karyology and distribution areas of cytotypes of Nannospalax leucodon (Rodentia: Spalacidae) in Western Anatolia. Acta Zool. Bulgar., 62: 161-167.

Kassambara A., 2016. GGCORRPLOT: Visualization of a correlation matrix using 'ggplot2'. R Package, version $\quad 0.1 .1$ https://CRAN.R-project.org/ package $=$ ggcorrplot

Kassambara, A. and Mundt, F., 2016. Factoextra: Extract and visualize the results of multivariate data analyses. R Package, version 1.0.3. https:// CRAN.R-project.org/package $=$ factoextra

Kenagy, G., 1973. Daily and seasonal patterns of activity and energetics in a heteromyid rodent community. Ecology, 54: 1201-1219. https://doi. org $/ 10.2307 / 1934184$

Kenagy, G., 1976. Field observations of male fighting, drumming, and copulation in the great basin kangaroo rat, Dipodomys microps. J. Mammal., 57: 781-785. https://doi.org/10.2307/1379458

Kimchi, T. and Terkel, J., 2002. Seeing and not seeing. Curr. Opin. Neurobiol., 12: 728-734. https://doi. org/10.1016/S0959-4388(02)00381-1

Kimchi, T. and Terkel, J., 2003. Mole rats (Spalax ehrenbergi) select bypass burrowing strategies in accordance with obstacle size. Naturwissenschaften, 90: $36-39$.

Kimchi, T., Reshef, M. and Terkel, J., 2005. Evidence for the use of reflected self-generated seismic waves for spatial orientation in a blind subterranean mammal. J. exp. Biol., 208: 647-659. https://doi. org/10.1242/jeb.01396

Kryštufek, B., Ivanitskaya, E., Arslan, A., Arslan, E. and Bužan, E.V., 2012. Evolutionary history of mole rats (genus Nannospalax) inferred from mitochondrial cytochrome b sequence. Biol. J. Linn. Soc., 105: 446-455. https://doi.org/10.1111/ j.1095-8312.2011.01795.x

Kryštufek, B. and Vohrảlik, V., 2009. Mammals of Turkey and Cyprus. Rodentia II: Cricetinae, Muridae, Spalacidae, Calomyscidae, Hystricidae, Castoridae. Bibliotheca Annales Majora, Koper. 
Lange, S., Burda, H., Wegner, R.E., Dammann, P, Begall, S. and Kawalika, M., 2007. Living in a "stethoscope": Burrow-acoustics promote auditory specializations in subterranean rodents. Naturwissenschaften, 94: 134-138. https://doi. org/10.1007/s00114-006-0168-0

Leary, S., Underwood, W, Anthony, R., Cartner, S., Corey, D., Grandin, T., Greenacre, C.B., GwaltneyBran, S., McCrackin, M.A. and Meyer, R., 2013. AVMA guidelines for the euthanasia of animals, 2013 edition. American Veterinary Medical Association, Schaumburg, IL.

Li, J., Wang, T., He, J. and Min, Y., 2001. Seismic communication in subterranean Gansu zokor (Myospalax cansus). Acta Theor. Sin., 21: 153-154.

Marchetti, K., 1993. Dark habitats and bright birds illustrate the role of the environment in species divergence. Nature, 362: 149-152. https://doi. org/10.1038/362149a0

Mason, M.J. and Narins, P.M., 2001. Seismic signal use by fossorial mammals. Am. Zool., 41: 1171-1184. https://doi.org/10.1093/icb/41.5.1171

Matur, F. and Sözen, M., 2005. A karyological study on subterrranean mole rats of the Spalax leucodon Nordmann, 1840 (Mammalia: Rodentia) superspecies in North-western Turkey. Zool. Middle East, 36: 5-10. https://doi.org/10.1080/09397140. 2005.10638121

Matur, F., Çolak, F., Ceylan, T., Sevindik, M. and Sözen, M., 2013. Chromosomal evolution in the genus Nannospalax (Mammalia: Rodentia) from West Turkiye. Turk. J. Zool., 37: 470-487. https:// doi.org/10.3906/zoo-1208-25

Matur, F., Yanchukov, A., Çolak, F. and Sözen, M., 2019. Two major clades of blind mole rats (Nannospalax sp.) revealed by mtDNA and microsatellite genotyping in Western and Central Turkey. Mammal. Biol., 94: 1-10. https://doi.org/10.1016/j. mambio.2018.11.004

Nevo, E., 1961. Observations on Israeli populations of the mole rat Spalax ehrenbergi Nehring 1898. Mammalia, 25: 127-144. https://doi.org/10.1515/ mamm.1961.25.2.127

Nevo, E., 1985. Speciation in action and adaptation in subterranean mole rats: Patterns and theory. Ital. J. Zool., 52: 65-95. https://doi. org/10.1080/11250008509440344

Nevo, E., 1990. Evolution of nonvisual communication and photoperiodic perception in speciation and adaptation of blind subterranean mole rats. Behaviour, 114: 249-276. https://doi. org/10.1163/156853990X00158
Nevo, E., Heth, G., Beiles, A. and Frankenberg, E., 1987. Geographic dialects in blind mole rats: Role of vocal communication in active speciation. Proc. natl. Acad. Sci. U.S.A., 84: 3312-3315. https://doi. org/10.1073/pnas.84.10.3312

Puzachenko, A.Y., 1996. The demographic structure and reproduction in the population of mole rat Spalax microphthalmus (Rodentia, Spalacidae). Zool. J., 75: 278-279.

R Development Core Team, 2016. $R$ : A Language and Environment for Statistical Computing, Version 3.12. R Foundation for Statistical Computing, Vienna, Austria. Retrieved from http://www.Rproject.org

Rado, R., Levi, N., Hauser, H., Witcher, J., Alder, N., Intrator, N., Wollberg, Z. and Terkel, J., 1987. Seismic signalling as a means of communication in a subterranean mammal. Anim. Behav., 35: 1249-1251. https://doi.org/10.1016/S00033472(87)80183-5

Randall, J.A., 1991. Mating strategies of a nocturnal, desert rodent (Dipodomys spectabilis. Behav. Ecol. Sociobiol., 28: 215-220. https://doi.org/10.1007/ BF00172173

Randall, J.A., 1995. Modification of foot drumming signatures by kangaroo rats: Changing territories and gaining new neighbours. Anim. Behav., 49: 12271237. https://doi.org/10.1006/anbe.1995.0155

Randall, J.A., 1997. Species-specific foot drumming in kangaroo rats: Dipodomys ingens, D. deserti. Anim. Behav., 54: 1167-1175. https://doi.org/10.1006/ anbe. 1997.0560

Randall, J.A. and Stevens, C.M., 1987. Foot drumming and other anti-predator responses. Behav. Ecol. Sociobiol., 20: 187-194. https://doi.org/10.1007/ BF00299732

Randall, J.A. and Matocq, M.D., 1997. Why do kangaroo rats (Dipodomys spectabilis) foot drum at snakes? Behav. Ecol., 8: 404-413. https://doi. org/10.1093/beheco/8.4.404

Riley, R., 2008. Audio editing with Adobe audition. PC Publishing.

Ryan, M.J.O. and Rand, A.S., 1993. Species recognition and sexual selection as a unitary problem in animal communication. Evolution, 47: 647-657. https:// doi.org/10.1111/j.1558-5646.1993.tb02118.x

Seehausen, O., van Alphen, J.J.M. and Witte, F., 1997. Cichlid fish diversity threatened by eutrophication that curbs sexual selection. Science, 277: 1808-1811. https://doi.org/10.1126/science.277.5333.1808

Sözen, M., 2004. A karyological study on subterranean mole rats of the Spalax leucodon Nordmann, 
1840 superspecies in Turkey. Mammal. Biol. Z. Säugetierk., 69: 420-429. https://doi. org/10.1078/1616-5047-00164

Sözen, M., Matur, F., Colak, E., Ozkurt, S. and Karatas, A., 2006. Some karyological records and a new chromosomal form for Spalax (Mammalia: Rodentia) in Turkey. Folia Zool., 55: 247.

SPSS, 1990. Statistical package for social science. SPSS Inc., Chicago, IL.

Ward, D.W. and Randall, J.A., 1987. Territorial defense in the bannertail kangaroo rat (Dipodomys spectabilis): Foot-drumming and visual threats. Behav. Ecol. Sociobiol., 20: 323-328. https://doi. org/10.1007/BF00300678

Yiğit, N., Çolak, E., Sözen, M. and Karataş A., 2006. Rodents of Türkiye. Meteksan, Ankara.

Zuri, I. and Terkel, J., 1996. Locomotor patterns, territory, and tunnel utilization in the mole rat Spalax ehrenbergi. J. Zool., 240: 123-140. https:// doi.org/10.1111/j.1469-7998.1996.tb05490.x 